\title{
Aptidões de genótipos de batata-doce para consumo humano, produção de etanol e alimentação animal
}

\author{
Álvaro Carlos Gonçalves Neto(1), Wilson Roberto Maluf(1), Luiz Antonio Augusto Gomes(1), \\ Ranoel José de Sousa Gonçalves ${ }^{(2)}$, Vanisse de Fátima Silva ${ }^{(3)}$ e André Lasmar ${ }^{(1)}$ \\ (1)Universidade Federal de Lavras (Ufla), Departamento de Agricultura, Caixa Postal 3037, CEP $37200-000$ Lavras, MG. \\ E-mail: alvarocgneto@gmail.com, wrmaluf@ufla.br, laagomes@ufla.br, andre_lasmar@yahoo.com.br(2)Ufla, Departamento de Biologia. \\ E-mail: ranoelgoncalves@hotmail.com ${ }^{(3)}$ Instituto Federal Goiano, Campus Rio Verde, Caixa Postal 66, CEP 75901-970 Rio Verde, GO. \\ E-mail: vanissesilva@yahoo.com
}

\begin{abstract}
Resumo - O objetivo deste trabalho foi identificar a aptidão de genótipos de batata-doce (Ipomoea batatas) para consumo humano, produção de etanol e alimentação animal, por meio de índices de aptidão. Os índices de aptidão corresponderam às médias dos valores das variáveis padronizadas para 16 características de interesse, ponderadas por pesos atribuídos a cada característica, conforme a aptidão avaliada. Utilizou-se o delineamento experimental de blocos ao acaso, com duas repetições e 39 genótipos: 36 acessos da coleção de germoplasma da Universidade Federal de Lavras e três cultivares comerciais (Palmas, Brazlândia-Branca e Brazlândia-Rosada). Oito genótipos foram considerados aptos à produção de etanol, 11 à alimentação animal e 11 ao consumo humano, incluindo as cultivares Palmas e Brazlândia-Branca. Os acessos UFLA07-12, UFLA07-31, UFLA07-43, UFLA07-49 e UFLA07-53 apresentaram aptidão para produção de etanol, alimentação animal e consumo humano. O índice de seleção é eficiente para estabelecer aptidões para genótipos de batata-doce.
\end{abstract}

Termos para indexação: Ipomoea batatas, biocombustível, índice de seleção, produção de biomassa, produção de ramas, qualidade nutricional.

\section{Aptitudes of sweet potato genotypes for fresh consumption, ethanol production and animal feed}

\begin{abstract}
The objective of this work was to identify agronomic aptitudes of sweet potato (Ipomoea batatas) genotypes for fresh consumption, ethanol production, and animal feed, using aptitude indices. The aptitude indices were established as the weighted means of standardized variables for 16 traits of interest, using different weights for each trait according to the evaluated aptitude. The experimental design was a completely randomized block, with two replicates and 39 sweet potato genotypes: 36 accessions of the germplasm collection of Universidade Federal de Lavras (Brazil) and three commercial cultivars (Palmas, Brazlândia-Branca e Brazlândia-Rosada). Eight genotypes were considered apt to ethanol production, 11 to animal feed, and 11 to human consumption, including the cultivars Palmas and Brazlândia-Branca. The accessions UFLA07-12, UFLA07-31, UFLA07-43, UFLA07-49, and UFLA07-53 showed aptitude for ethanol production, animal feed and human consumption. The selection index is efficient in establishing aptitudes for sweet potato genotypes.
\end{abstract}

Index terms: Ipomoea batatas, biofuel, selection index, biomass yield, stem yield, nutritional quality.

\section{Introdução}

A batata-doce (Ipomoea batatas L.) pode ser aproveitada na alimentação humana (raízes), na alimentação animal (raízes e parte aérea) e na produção de etanol (raízes). Embora ainda seja pouco utilizada para essa última finalidade, a espécie apresenta grande potencial para produção de álcool no Brasil. Cultivares de batata-doce, obtidas por meio de melhoramento genético, têm apresentado índices de produção etílica por hectare duas vezes maior que os de cana-de-açúcar (Silveira, 2008).
$\mathrm{Na}$ alimentação animal, as raízes são utilizadas essencialmente como fonte de energia, em virtude do baixo teor de proteína. No entanto, as ramas que contêm, em média, $11,4 \%$ de proteína na matéria seca também podem ser aproveitadas (Massaroto, 2008). No Brasil, a utilização de ramas de batata-doce na alimentação animal ainda é feita em escala bastante limitada.

Por apresentar grande variabilidade genética, a batata-doce permite seleção para inúmeros propósitos, como: obtenção de materiais resistentes a pragas e doenças (Azevedo et al., 2002), com melhor qualidade nutricional (maior teor de vitamina $\mathrm{A}$ ); maior densidade

Pesq. agropec. bras., Brasília, v.46, n.11, p.1513-1520, nov. 2011 
de raízes (Cardoso et al., 2007); maior teor de matéria seca e produção de biomassa, que podem proporcionar maior rendimento para produção de álcool; e maior produção de ramas, para alimentação animal.

Entretanto, a seleção para apenas um desses usos pode levar à inaptidão agronômica para outras finalidades, pois a seleção com base em um ou poucos caracteres pode resultar em alterações desfavoráveis nos demais, já que existem correlações genéticas negativas entre eles, o que torna necessário o uso de índices para a seleção baseada em um conjunto de variáveis que reúna vários atributos de interesse econômico (Cruz \& Regazzi, 2002). Assim, o índice passa a ser considerado um parâmetro adicional, estabelecido pela combinação linear ótima de diversos caracteres preferencialmente não correlacionados (Barbosa \& Pinto, 1998). Porém, a utilização desses índices é limitada, em razão da dificuldade de estabelecimento de pesos econômicos adequados aos vários caracteres.

A maioria das cultivares atualmente utilizadas foi selecionada para o consumo humano principalmente. Contudo, o enorme potencial da cultura para produção de etanol, bem como para alimentação animal, torna cada vez mais necessária a identificação das aptidões agronômicas desses materiais para outras finalidades.

O objetivo deste trabalho foi identificar a aptidão de genótipos de batata-doce (Ipomoea batatas) para consumo humano, produção de etanol e alimentação animal, por meio de índices de aptidão.

\section{Material e Métodos}

O ensaio foi instalado no campo experimental da empresa HortiAgro Sementes Ltda., localizada na Fazenda Palmital, no Município de Ijaci, MG (21ํ14'16"S e $45^{\circ} 08^{\prime} 00^{\prime \prime} \mathrm{W}$, a $918 \mathrm{~m}$ de altitude), no período de março a outubro de 2007. O solo, que apresentava acidez corrigida e média fertilidade, foi submetido a uma aração e a duas gradagens. Em seguida, foram levantados camalhões com $40 \mathrm{~cm}$ de altura, adubados com $1.000 \mathrm{~kg} \mathrm{ha}^{-1}$ da fórmula N-P-K 4-14-8. Dois meses após o plantio, foi realizada adubação de cobertura com $1.000 \mathrm{~kg} \mathrm{ha}^{-1}$ de ureia.

Foram avaliados 39 genótipos de batata-doce (Tabela 1): 36 acessos pertencentes à coleção de germoplasma da Universidade Federal de Lavras (Ufla) e três cultivares comerciais como testemunhas (Palmas, Brazlândia-Branca e Brazlândia-Rosada). Utilizou-se o delineamento experimental de blocos ao acaso, com duas repetições. As parcelas foram compostas de leiras com
12 plantas, no espaçamento de $0,80 \mathrm{~m}$ entre leiras e $0,4 \mathrm{~m}$ entre plantas, com utilização de bordadura nas fileiras externas do experimento. No plantio, foram utilizadas estacas de caule (ramas) com aproximadamente seis gemas, das quais três foram enterradas no solo. O ensaio foi conduzido sob condições de irrigação por aspersão, e a colheita foi realizada sete meses após o plantio, tendose avaliado todas as parcelas.

Foram avaliadas as seguintes características: produção total de raízes frescas (massa total de raízes colhidas por parcela); percentagem de matéria seca das raízes (amostras das raízes de cada parcela trituradas e secas em estufa a $65^{\circ} \mathrm{C}$, até atingir massa constante); produtividade $\left(\mathrm{Mg} \mathrm{ha}{ }^{-1}\right)$ de matéria seca de raízes (produto entre percentagem de matéria seca nas raízes e produção total de raízes); densidade de raízes, determinada pelo método da balança hidrostática (Centro Internacional de la Papa, 2001); produção de matéria fresca de parte aérea (massa da parte aérea de cada parcela); percentagem de matéria seca da parte aérea (amostras da parte aérea trituradas e secas em estufa a $65^{\circ} \mathrm{C}$, até atingir massa constante); produtividade $\left(\mathrm{Mg} \mathrm{ha}^{-1}\right)$ de matéria seca da parte aérea (produto entre percentagem de matéria seca na parte aérea e produção total da parte aérea); produção de raízes comerciais (com formato uniforme e massa igual ou superior a $100 \mathrm{~g}$, em oposição às não comerciais, com raízes pequenas, muito longas, tortuosas ou muito danificadas por pragas, com massa inferior a $100 \mathrm{~g}$ ); e percentagem de raízes comerciais (relação entre produção total de raízes frescas e produção de raízes comerciais). Também foram avaliados: doçura das raízes ao paladar, após cozimento, por avaliação sensorial por provador, em que foram atribuídas notas de 1, pouco doce, a 5, muito doce; formato de raízes, determinado por meio de escala de notas de 1, excelente, a 5, péssimo, conforme Azevedo et al. (2000); manchas roxas nas raízes (duas raízes de cada parcela foram cortadas para observação da presença de manchas roxas na polpa, por meio de escala de notas, em que: 1, nenhuma mancha; 3, algumas manchas; e 5, mancha totalmente roxa. Quanto a esse caráter, valores baixos foram considerados desejáveis para consumo humano); escurecimento de raízes (duas raízes de cada parcela foram cortadas e, após cerca de $1 \mathrm{~min}$, foram atribuídas notas, para escurecimento enzimático, de 1, sem escurecimento, a 5, com escurecimento. Valores baixos foram considerados desejáveis); látex nas raízes (duas raízes de cada parcela foram cortadas na porção 
média da raiz e, após cerca de $1 \mathrm{~min}$, foram atribuídas notas de 1 , nenhum látex, a 5 , muito látex presente. Valores baixos foram considerados desejáveis); umidade das raízes ao paladar (avaliação sensorial por dois provadores treinados, após cozimento das raízes, em que foram atribuídas notas de 1 , muito seca, a 5, muito úmida. Valores baixos foram considerados desejáveis, em razão da preferência do consumidor brasileiro por batatas de

Tabela 1. Descrição dos genótipos de batata doce utilizados no experimento.

\begin{tabular}{|c|c|c|}
\hline Acesso & Denominação $^{(1)}$ & Procedência \\
\hline- & 'Palmas' & UFT, TO \\
\hline - & 'Brazlândia-Branca' & EMBRAPA \\
\hline- & 'Brazlândia-Rosada' & EMBRAPA \\
\hline UFLA07-01 & 'Coração-Magoado' & UFVJM, MG \\
\hline UFLA07-02 & DIA-BD-07 & UFVJM, MG \\
\hline UFLA07-03 & 'Cambraia' & UFVJM, MG \\
\hline UFLA07-04 & 'Arruba' & UFVJM, MG \\
\hline UFLA07-05 & 'Licuri' & UFVJM, MG \\
\hline UFLA07-08 & DIA-BD-24 & UFVJM, MG \\
\hline UFLA07-09 & 'Princesa' & UFVJM, MG \\
\hline UFLA07-10 & DIA-BD-12 & UFVJM, MG \\
\hline UFLA07-11 & 'Tomba-carro' & UFVJM, MG \\
\hline UFLA07-12 & DIA-BD-06 & UFVJM, MG \\
\hline UFLA07-14 & DIA-BD-56 & UFVJM, MG \\
\hline UFLA07-15 & DIA-BD-42 & UFVJM, MG \\
\hline UFLA07-16 & DIA-BD-15 & UFVJM, MG \\
\hline UFLA07-17 & DIA-BD-25 & UFVJM, MG \\
\hline UFLA07-18 & 'Marmel' & UFVJM, MG \\
\hline UFLA07-19 & DIA-BD-45 & UFVJM, MG \\
\hline UFLA07-20 & DIA-BD-39 & UFVJM, MG \\
\hline UFLA07-21 & DIA-BD-65 & UFVJM, MG \\
\hline UFLA07-22 & DIA-BD-46 & UFVJM, MG \\
\hline UFLA07-23 & UFT-BD-14-Al & UFT, TO \\
\hline UFLA07-24 & DIA-BD-67 & UFVJM, MG \\
\hline UFLA07-26 & DIA-BD-31 & UFVJM, MG \\
\hline UFLA07-27 & DIA-BD-14 & UFVJM, MG \\
\hline UFLA07-29 & DIA-BD-11 & UFVJM, MG \\
\hline UFLA07-31 & DIA-BD-38 & UFVJM, MG \\
\hline UFLA07-37 & UFT-BD-115 & UFT, TO \\
\hline UFLA07-40 & UFT-BD-35-Al & UFT, TO \\
\hline UFLA07-41 & DIA-BD-54 & UFVJM, MG \\
\hline UFLA07-42 & UFT-BD-58 & UFT, TO \\
\hline UFLA07-43 & UFT-BD-02-Al & UFT, TO \\
\hline UFLA07-45 & UFT-BD-09-Al & UFT, TO \\
\hline UFLA07-46 & UFT-BD-52 & UFT, TO \\
\hline UFLA07-48 & 'Canuanã' & UFT, TO \\
\hline UFLA07-49 & UFT-BD-04-Al & UFT, TO \\
\hline UFLA07-51 & UFT-BD-100 & UFT, TO \\
\hline UFLA07-53 & UFT-BD-08 & UFT, TO \\
\hline
\end{tabular}

(1) As cultivares comerciais Palmas, Brazlândia-Branca e Brazlândia-Rosada foram consideradas testemunhas. UFT, Universidade Federal do Tocantins; UFVJM, Universidade Federal dos Vales do Jequitinhonha e Mucurí. polpa seca); fibra nas raízes (avaliação sensorial por dois provadores treinados, após cozimento, por meio de escala de notas de 1, pouca fibra, a 5, muita fibra. Valores baixos foram considerados desejáveis); cor de polpa das raízes (após o cozimento, raízes de cada parcela foram cortadas e classificadas de acordo com as seguintes cores: branco, creme, creme-escuro, amarelo-claro, amarelo-escuro, roxo-claro, roxo-escuro, laranjaclaro e laranja-escuro. As colorações amarelo-claro, amarelo-escuro, laranja-claro e laranja-escuro são consideradas desejáveis para consumo humano, uma vez que são mais ricas em betacaroteno (Almeida-Muradian \& Penteado, 1992; Hagenimana et al., 1998) e, portanto, apresentam maior valor nutricional.

Para a elaboração dos índices de aptidão, as médias dos tratamentos para cada característica foram padronizadas, por meio da expressão: $Z_{i}=\left(\bar{X}_{i}-\bar{X}\right) / S$, em que: $Z_{i}$ é o valor da variável padronizada correspondente ao tratamento $\mathrm{i} ; \overline{\mathrm{X}}_{\mathrm{i}}$ é a média do tratamento $i$; $\bar{X}$ é a média geral; $\mathrm{S}$ é o desvio padrão fenotípico entre os tratamentos. Para cada uma das aptidões propostas (consumo humano, produção de etanol e alimentação animal), foi estimado um índice de seleção que correspondeu à ponderação das médias das variáveis padronizadas $\left(\mathrm{Z}_{\mathrm{i}}\right)$ por pesos atribuídos a cada característica, conforme cada aptidão (Tabela 2). As ponderações indicadas representaram a importância

Tabela 2. Pesos atribuídos às características de relevância para cada uma das aptidões avaliadas, em batata-doce.

\begin{tabular}{lccc}
\hline Características & $\begin{array}{c}\text { Produção } \\
\text { de etanol }\end{array}$ & $\begin{array}{c}\text { Alimentação } \\
\text { animal }\end{array}$ & $\begin{array}{c}\text { Consumo } \\
\text { humano }\end{array}$ \\
\hline Produção total de raízes frescas & 5 & 5 & 0 \\
Matéria seca nas raízes (\%) & 3 & 3 & 0 \\
Matéria seca nas raízes (Mg) & 15 & 10 & 0 \\
Densidade das raízes & 3 & 0 & 0 \\
Produção de MF da parte aérea & 0 & 5 & 0 \\
Matéria seca na parte aérea (\%) & 0 & 3 & 0 \\
Matéria seca na parte aérea (Mg) & 0 & 15 & 0 \\
Produção de raízes comerciais & 0 & 0 & 15 \\
Produção de raízes comerciais (\%) & 0 & 0 & 2 \\
Doçura das raízes ao paladar & 0 & 0 & 5 \\
Formato de raízes & 0 & 0 & -5 \\
Manchas roxas nas raízes & 0 & 0 & -1 \\
Escurecimento de raízes & 0 & 0 & -1 \\
Látex nas raízes & 0 & 0 & -1 \\
Umidade das raízes ao paladar & 0 & 0 & -3 \\
Fibra nas raízes & 0 & 0 & -3 \\
\hline Total dos pesos & 26 & 41 & 36 \\
\hline
\end{tabular}

(1)Pesos negativos, uma vez que altos valores absolutos são considerados indesejáveis. MF, matéria fresca. 
relativa de cada característica para o índice de aptidão considerado. Assim, a produção total de matéria seca nas raízes foi o fator com maior ponderação na aptidão para etanol biocombustível, seguida da produção total de raízes (comerciais ou não), da percentagem de matéria seca e da densidade das raízes. Quanto à aptidão para mesa, destacou-se a produção de raízes comerciais, seguida de características relacionadas à qualidade sensorial. Para alimentação animal, tiveram destaque as produções de matéria seca na parte aérea e nas raízes.

Os pesos atribuídos foram negativos para as características formato de raízes, manchas roxas nas raízes, escurecimento de raízes, látex nas raízes, umidade das raízes ao paladar e fibra nas raízes, para as quais os valores numericamente altos são considerados indesejáveis.

Foram considerados aptos os genótipos que atingiram índice de seleção igual ou superior à média $+0,6745$ unidades de desvio-padrão, o que corresponde, na distribuição normal, à seleção dos melhores $25 \%$ em cada aptidão.

\section{Resultados e Discussão}

Os genótipos de batata-doce apresentaram grande variabilidade para as características analisadas (Tabela 3). Alguns genótipos apresentaram múltiplas aptidões (consumo humano, produção de etanol e alimentação animal), enquanto outros apresentaram apenas uma ou nenhuma aptidão (não recomendados para cultivo).

Os índices de aptidão para a produção de etanol biocombustível variaram de valores negativos $(-1,08$ para UFLA07-14) a valores positivos (2,62 para UFLA07-43). O índice-limite inferior estabelecido para a seleção de genótipos superiores foi de 0,51 . Portanto, os genótipos UFLA07-05, UFLA07-10, UFLA07-12, UFLA07-24, UFLA07-31, UFLA07-43, UFLA07-49 e UFLA07-53 foram considerados com aptidão para a produção de etanol (Tabela 3). Esses genótipos revelaram-se potencialmente competitivos com a própria cana-de-açúcar, para essa finalidade. A cana-de-açúcar, com elevada produtividade (100 $\mathrm{Mg} \mathrm{ha}^{-1}$ de colmos e $90 \mathrm{~L}$ de etanol por megagrama), atinge a produção de $9.000 \mathrm{~L} \mathrm{ha}^{-1}$ de etanol, em ciclo de 12 meses (Bioetanol de cana de açúcar, 2008). Os genótipos de batata-doce considerados aptos para produção de etanol, com base na produção de $158 \mathrm{~L}$ de etanol por megagrama de raízes processadas (Silveira, 2008), apresentam produção etanólica entre 7.078,4 e 15.484,0 L ha ${ }^{-1}$ correspondentes à amplitude de produtividade de $44,8 \mathrm{e}$ $98,0 \mathrm{Mg} \mathrm{ha}^{-1}$ de raízes, respectivamente (Tabelas 3 e 4). A superioridade de produção de etanol dos genótipos de batata-doce considerados aptos para essa finalidade, em comparação à cana-de-açúcar, evidencia a eficiência do índice de seleção proposto neste trabalho.

Para alimentação animal, os índices de aptidão variaram de -1,03 (UFLA07-14) a +1,56 (UFLA07-43), e o índice-limite para seleção dos genótipos superiores foi de 0,47. Assim, os genótipos UFLA07-08, UFLA07-12, UFLA07-15, UFLA07-18, UFLA07-21, UFLA07-24, UFLA07-27, UFLA07-31, UFLA07-43, UFLA07-49 e UFLA07-53 foram considerados aptos para alimentação animal (Tabela 3). Ao considerar-se que a massa de matéria seca da parte aérea de batata-doce tenha, em média, 11,4\% de teor proteico (Massaroto, 2008), a média da produção total de proteína bruta nas ramas dos 11 genótipos $\left(25,44 \mathrm{Mg} \mathrm{ha}^{-1}\right.$ de matéria seca na parte aérea) foi superior ao dobro da média de

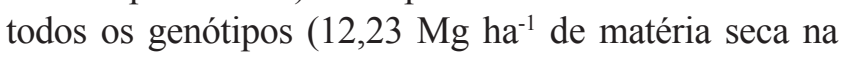
parte aérea dos 39 clones analisados) e três vezes maior que os valores alcançados pela média dos não aptos (7.080 $\mathrm{Mg} \mathrm{ha}^{-1}$ de matéria seca na parte aérea dos 28 clones não aptos para alimentação animal), o que indica mais uma vez a eficiência do índice de seleção, agora utilizado para a identificação de genótipos com aptidão para alimentação animal.

A produtividade em proteína bruta nas ramas dos 11 genótipos de batata-doce, aptos para alimentação animal, superou a produção de proteína bruta estimada na literatura para as culturas de soja, milho e feijão (Tanaka et al., 1995; Lemos et al., 2004; Amaral Filho et al., 2005). Esse potencial já havia sido relatado por Ruiz et al. (1980) que, ao avaliar duas cultivares de batata-doce colhidas seis meses após o plantio, obtiveram produção para forragem de 4.305 e $5.979 \mathrm{~kg} \mathrm{ha}^{-1}$ de matéria seca e teor de proteína bruta de 12,2 , e $17,3 \%$, o que equivale a 525,2 e $1.034,4 \mathrm{~kg}$ de proteína bruta por hectare de parte aérea.

Nenhuma das três testemunhas comerciais ('Palmas', 'Brazlândia-Branca' e 'Brazlândia-Rosada') foi classificada como apta para produção de etanol ou alimentação animal, pois essas cultivares foram obtidas em programas de melhoramento genético voltados unicamente para seleção de características relacionadas ao consumo humano. 
Para aptidão de produção de raízes destinadas ao consumo humano, o índice de seleção não variou tanto quanto nas demais características (Tabela 3). O pior desempenho foi alcançado pelo genótipo UFLA07-22 $(-0,64)$, e o genótipo com melhor desempenho foi o UFLA07-12 (1,29). Como o índice limite para seleção estabelecido foi de 0,31 , os genótipos UFLA07-01, UFLA07-05, UFLA07-12, UFLA07-16,
UFLA07-31, UFLA07-42, UFLA07-43, UFLA07-49 e UFLA07-53 e as testemunhas comerciais 'Palmas' e 'Brazlândia-Branca' apresentaram boa combinação das características agronômicas desejáveis para consumo humano (Tabela 3). No entanto, a cultivar comercial Brazlândia-Rosada não foi considerada apta para consumo humano em razão, principalmente, da baixa produção de raízes comerciais (Tabela 4).

Tabela 3. Índice de seleção e classificação dos genótipos de batata-doce utilizados quanto às suas aptidões.

\begin{tabular}{|c|c|c|c|c|c|c|c|}
\hline \multirow[t]{2}{*}{ Genótipo } & \multicolumn{2}{|c|}{ Produção de etanol } & \multicolumn{2}{|c|}{ Alimentação animal } & \multicolumn{2}{|c|}{ Consumo humano } & \multirow{2}{*}{$\begin{array}{l}\text { Coloração da polpa } \\
\text { após cozimento }\end{array}$} \\
\hline & Índice & Status & Índice & Status & Índice & Status & \\
\hline 'Palmas' & 0,05 & - & $-0,19$ & - & 0,47 & Apto & Creme \\
\hline 'Brazlândia-Branca' & $-0,04$ & - & $-0,40$ & - & 0,31 & Apto & Creme \\
\hline 'Brazlândia-Rosada' & $-0,60$ & - & 0,17 & - & $-0,20$ & - & Amarelo-claro \\
\hline UFLA07-01 & 0,17 & - & $-0,08$ & - & 0,41 & Apto & Amarelo-claro \\
\hline UFLA07-02 & $-0,48$ & - & $-0,53$ & - & $-0,02$ & - & Amarelo-claro \\
\hline UFLA07-03 & $-0,11$ & - & $-0,40$ & - & $-0,38$ & - & Creme \\
\hline UFLA07-04 & 0,37 & - & 0,10 & - & 0,28 & - & Creme \\
\hline UFLA07-05 & 0,54 & Apto & 0,41 & - & 0,34 & Apto & Creme \\
\hline UFLA07-08 & $-0,46$ & - & 0,83 & Apto & $-0,34$ & - & Amarelo-claro \\
\hline UFLA07-09 & $-0,49$ & - & $-0,67$ & - & $-0,09$ & - & Branco \\
\hline UFLA07-10 & 0,78 & Apto & 0,19 & - & $-0,27$ & - & Creme-escuro \\
\hline UFLA07-11 & $-0,49$ & - & 0,01 & - & $-0,19$ & - & Branco \\
\hline UFLA07-12 & 1,68 & Apto & 1,19 & Apto & 1,29 & Apto & Branco \\
\hline UFLA07-14 & $-1,08$ & - & $-1,03$ & - & $-0,30$ & - & Creme \\
\hline UFLA07-15 & 0,23 & - & 1,05 & Apto & 0,10 & - & Roxo-claro \\
\hline UFLA07-16 & 0,21 & - & $-0,05$ & - & 0,36 & Apto & Creme \\
\hline UFLA07-17 & $-0,79$ & - & $-0,29$ & - & $-0,60$ & - & Amarelo-claro \\
\hline UFLA07-18 & $-0,02$ & - & 0,54 & Apto & $-0,56$ & - & Branco \\
\hline UFLA07-19 & $-0,14$ & - & $-0,23$ & - & 0,01 & - & Creme \\
\hline UFLA07-20 & $-0,66$ & - & $-0,59$ & - & $-0,58$ & - & Amarelo-claro \\
\hline UFLA07-21 & 0,04 & - & 0,96 & Apto & $-0,39$ & - & Roxo-escuro \\
\hline UFLA07-22 & $-0,72$ & - & $-0,79$ & - & $-0,64$ & - & Creme \\
\hline UFLA07-23 & $-0,79$ & - & $-0,52$ & - & $-0,25$ & - & Amarelo-claro \\
\hline UFLA07-24 & 0,53 & Apto & 1,34 & Apto & 0,29 & - & Branco \\
\hline UFLA07-26 & $-0,83$ & - & $-0,88$ & - & $-0,49$ & - & Creme \\
\hline UFLA07-27 & 0,49 & - & 0,92 & Apto & $-0,11$ & - & Creme \\
\hline UFLA07-29 & 0,37 & - & 0,23 & - & 0,22 & - & Laranja \\
\hline UFLA07-31 & 0,68 & Apto & 0,64 & Apto & 0,54 & Apto & Creme \\
\hline UFLA07-37 & $-0,36$ & - & $-0,49$ & - & $-0,04$ & - & Creme \\
\hline UFLA07-40 & $-0,67$ & - & $-0,89$ & - & $-0,22$ & - & Laranja-escuro \\
\hline UFLA07-41 & $-0,55$ & - & $-0,23$ & - & $-0,16$ & - & Creme-claro \\
\hline UFLA07-42 & 0,46 & - & 0,03 & - & 0,35 & Apto & Creme \\
\hline UFLA07-43 & 2,62 & Apto & 1,56 & Apto & 0,65 & Apto & Amarelo-claro \\
\hline UFLA07-45 & $-0,56$ & - & $-0,93$ & - & $-0,40$ & - & Laranja \\
\hline UFLA07-46 & $-0,44$ & - & $-0,59$ & - & $-0,15$ & - & Creme \\
\hline UFLA07-48 & $-0,48$ & - & $-0,69$ & - & $-0,57$ & - & Creme \\
\hline UFLA07-49 & 1,44 & Apto & 0,58 & Apto & 1,03 & Apto & Amarelo-claro \\
\hline UFLA07-51 & $-0,61$ & - & $-0,78$ & - & $-0,20$ & - & Creme \\
\hline UFLA07-53 & 0,72 & Apto & 0,49 & Apto & 0,55 & Apto & Amarelo-claro \\
\hline Desvio-padrão & 0,76 & - & 0,70 & - & 0,45 & - & - \\
\hline Limite de aptidão $^{(1)}$ & 0,51 & - & 0,47 & - & 0,31 & - & - \\
\hline
\end{tabular}

${ }^{(1)}$ Limite acima do qual os genótipos são considerados aptos. 
Entre os genótipos com aptidão para consumo humano, alguns apresentaram alto valor nutricional, representado por polpas de coloração amarelada ou alaranjada após cozimento, mais ricas em betacaroteno (atividade provitamínica A) do que genótipos de polpa esbranquiçada ou creme. Portanto, dos 11 genótipos selecionados para consumo humano, quatro deles (UFLA07-01, UFLA07-43, UFLA07-49 e UFLA07-53) apresentaram coloração de polpa amarelo-clara e maior valor nutricional (Tabela 3). Também foram identificados genótipos (UFLA-07-29, UFLA-07-40 e UFLA-07-45) com coloração de polpa alaranjada mais intensa, os quais, no entanto, não apresentaram índices de seleção que permitissem sua indicação como genótipos aptos à cultura para consumo humano.

Duas características sensoriais são imprescindíveis para aceitação pelo mercado consumidor de batata-doce. A primeira é o grau de doçura, que é

Tabela 4. Médias de produção total e percentagem de matéria seca (MS), nas raízes e na parte aérea, e produção e percentagem de raízes comerciais nos genótipos de batata-doce avaliados.

\begin{tabular}{|c|c|c|c|c|c|c|c|c|}
\hline Genótipo & $\begin{array}{l}\text { Raízes frescas } \\
\left(\mathrm{Mg} \mathrm{ha}^{-1}\right)\end{array}$ & $\begin{array}{l}\text { MS } \\
(\%)\end{array}$ & $\begin{array}{l}\text { MS raízes } \\
\left(\mathrm{Mg} \mathrm{ha}^{-1}\right)\end{array}$ & $\begin{array}{l}\text { Parte aérea fresca } \\
\qquad\left(\mathrm{Mg} \mathrm{ha}^{-1}\right)\end{array}$ & $\begin{array}{l}\text { MS } \\
(\%)\end{array}$ & $\begin{array}{l}\text { MS aérea } \\
\left(\mathrm{Mg} \mathrm{ha}^{-1}\right)\end{array}$ & $\begin{array}{l}\text { Raízes comerciais } \\
\left(\mathrm{Mg} \mathrm{ha}^{-1}\right)\end{array}$ & $\begin{array}{c}\text { Raízes } \\
\text { comerciais }(\%)\end{array}$ \\
\hline 'Palmas' & 27,30 & 33,75 & 9,15 & 55,10 & 15,67 & 8,61 & 22,85 & 84,55 \\
\hline 'Brazlândia-Branca' & 28,00 & 30,35 & 8,50 & 39,60 & 14,12 & 5,50 & 24,60 & 86,40 \\
\hline 'Brazlândia-Rosada' & 11,30 & 37,45 & 4,25 & 101,80 & 19,63 & 20,01 & 7,80 & 69,65 \\
\hline UFLA07-01 & 42,40 & 28,05 & 12,05 & 39,15 & 16,69 & 6,66 & 30,40 & 70,80 \\
\hline UFLA07-02 & 12,80 & 38,60 & 4,95 & 40,00 & 15,35 & 6,21 & 9,05 & 71,15 \\
\hline UFLA07-03 & 24,70 & 32,50 & 7,85 & 13,95 & 19,53 & 2,74 & 8,50 & 39,00 \\
\hline UFLA07-04 & 52,70 & 24,77 & 12,86 & 76,84 & 13,93 & 10,30 & 16,53 & 33,36 \\
\hline UFLA07-05 & 44,80 & 31,90 & 14,30 & 76,25 & 18,23 & 14,21 & 26,75 & 59,90 \\
\hline UFLA07-08 & 17,20 & 30,95 & 5,35 & 201,55 & 17,18 & 34,83 & 7,45 & 44,30 \\
\hline UFLA07-09 & 17,10 & 24,07 & 3,96 & 33,84 & 14,75 & 4,25 & 12,13 & 68,26 \\
\hline UFLA07-10 & 46,70 & 31,35 & 14,65 & 73,00 & 14,91 & 10,71 & 19,30 & 41,75 \\
\hline UFLA07-11 & 17,40 & 32,60 & 5,70 & 102,85 & 16,28 & 16,59 & 6,75 & 38,25 \\
\hline UFLA07-12 & 98,00 & 23,60 & 23,20 & 136,85 & 14,97 & 20,00 & 51,35 & 51,50 \\
\hline UFLA07-14 & 3,70 & 21,47 & 0,55 & 15,04 & 14,27 & 1,24 & 1,03 & 33,56 \\
\hline UFLA07-15 & 30,80 & 32,55 & 9,95 & 302,45 & 11,45 & 34,41 & 12,20 & 37,40 \\
\hline UFLA07-16 & 45,70 & 26,65 & 12,00 & 51,95 & 15,13 & 7,84 & 30,65 & 68,40 \\
\hline UFLA07-17 & 6,00 & 33,45 & 2,00 & 67,00 & 18,83 & 12,86 & 3,70 & 61,40 \\
\hline UFLA07-18 & 28,40 & 35,30 & 10,10 & 160,10 & 14,79 & 23,68 & 8,35 & 28,75 \\
\hline UFLA07-19 & 26,90 & 29,80 & 7,65 & 84,70 & 12,63 & 10,61 & 14,50 & 51,20 \\
\hline UFLA07-20 & 8,20 & 34,25 & 2,80 & 22,25 & 19,56 & 4,35 & 4,90 & 60,00 \\
\hline UFLA07-21 & 15,50 & 45,10 & 6,95 & 219,85 & 16,15 & 36,08 & 5,10 & 32,55 \\
\hline UFLA07-22 & 6,10 & 43,57 & 2,96 & 7,74 & 18,35 & 0,55 & 5,63 & 76,26 \\
\hline UFLA07-23 & 8,20 & 34,05 & 2,85 & 29,45 & 19,57 & 5,91 & 6,75 & 82,90 \\
\hline UFLA07-24 & 46,20 & 30,85 & 14,30 & 236,45 & 15,00 & 36,10 & 23,50 & 51,35 \\
\hline UFLA07-26 & 3,00 & 42,77 & 1,66 & 20,84 & 14,72 & 2,21 & 2,13 & 56,26 \\
\hline UFLA07-27 & 44,90 & 29,40 & 13,05 & 146,45 & 18,40 & 26,80 & 27,35 & 61,10 \\
\hline UFLA07-29 & 42,00 & 31,45 & 13,05 & 72,00 & 17,06 & 12,23 & 21,85 & 51,25 \\
\hline UFLA07-31 & 56,80 & 27,65 & 15,70 & 117,40 & 15,41 & 18,61 & 27,10 & 47,95 \\
\hline UFLA07-37 & 18,20 & 28,00 & 5,15 & 6,30 & 22,66 & 1,45 & 13,45 & 73,65 \\
\hline UFLA07-40 & 7,30 & 27,40 & 2,05 & 14,35 & 14,76 & 2,13 & 4,30 & 58,30 \\
\hline UFLA07-41 & 7,20 & 40,30 & 2,90 & 86,45 & 16,58 & 14,11 & 2,55 & 34,95 \\
\hline UFLA07-42 & 42,80 & 28,85 & 12,30 & 53,45 & 16,36 & 8,81 & 35,65 & 83,90 \\
\hline UFLA07-43 & 95,10 & 32,90 & 31,60 & 115,40 & 17,55 & 20,25 & 42,70 & 44,00 \\
\hline UFLA07-45 & 3,85 & 29,70 & 1,15 & 3,20 & 17,85 & 0,57 & 2,20 & 57,65 \\
\hline UFLA07-46 & 22,00 & 28,25 & 6,20 & 19,70 & 15,54 & 3,04 & 19,65 & 89,15 \\
\hline UFLA07-48 & 16,90 & 28,87 & 4,86 & 24,14 & 15,01 & 2,81 & 0,00 & 0,00 \\
\hline UFLA07-49 & 64,30 & 32,70 & 21,00 & 84,00 & 14,50 & 12,32 & 44,50 & 69,50 \\
\hline UFLA07-51 & 14,30 & 21,75 & 3,10 & 10,25 & 16,88 & 1,72 & 14,30 & 99,45 \\
\hline UFLA07-53 & 45,50 & 31,60 & 14,45 & 102,90 & 16,39 & 16,83 & 26,05 & 57,80 \\
\hline Média & 29,51 & 31,50 & 8,90 & 78,58 & 16,32 & 12,23 & 16,50 & 57,12 \\
\hline Desvio-padrão & 23,19 & 31,44 & 6,69 & 70,04 & 2,20 & 10,52 & 13,05 & 20,26 \\
\hline
\end{tabular}


considerado satisfatório quando de médio a forte (Souza, 2000; Cardoso et al., 2007). No presente trabalho, a maioria dos genótipos apresentou bom grau de doçura (Tabela 5) - valores a partir da nota 2,5. Outra característica importante é o formato das raízes, para a qual muitos genótipos apresentaram notas superiores a 3 (Tabela 5).
Entre os 39 genótipos analisados, 21 não apresentaram nenhuma das aptidões previamente estabelecidas: UFLA07-02, UFLA07-03, UFLA07-04, UFLA07-09, UFLA07-11, UFLA07-14, UFLA07-17, UFLA07-19, UFLA07-20, UFLA07-22, UFLA07-23, UFLA07-26, UFLA07-29, UFLA07-37, UFLA07-40, UFLA07-41, UFLA07-45, UFLA07-46, UFLA07-48, UFLA07-51

Tabela 5. Média das características de densidade, doçura ao paladar, formato, manchas roxas, escurecimento, látex, umidade ao paladar e teor de fibras das raízes nos genótipos de batata-doce avaliados.

\begin{tabular}{|c|c|c|c|c|c|c|c|c|}
\hline \multirow[t]{2}{*}{ Genótipos } & \multirow[t]{2}{*}{ Densidade } & \multicolumn{7}{|c|}{ Características sensoriais $^{(1)}$} \\
\hline & & Doçura & Formato & Manchas roxas & Escurecimento & Látex & Umidade & Fibra \\
\hline 'Palmas' & 1,0565 & 4,5 & 3,5 & 1,50 & 3,0 & 2,0 & 3,5 & 2,0 \\
\hline 'Brazlândia-Branca' & 1,0524 & 2,5 & 3,0 & 1,50 & 3,0 & 3,0 & 4,5 & 1,5 \\
\hline 'Brazlândia-Rosada' & 1,0411 & 3,5 & 3,0 & 1,45 & 4,0 & 3,5 & 3,5 & 2,5 \\
\hline UFLA07-01 & 1,0231 & 2,5 & 3,5 & 1,33 & 3,5 & 3,5 & 2,5 & 2,5 \\
\hline UFLA07-02 & 1,0472 & 4,0 & 2,5 & 1,45 & 4,0 & 2,5 & 2,0 & 3,5 \\
\hline UFLA07-03 & 1,0540 & 3,0 & 3,5 & 1,50 & 3,0 & 1,5 & 2,0 & 4,5 \\
\hline UFLA07-04 & 1,0302 & 5,0 & 2,9 & 1,50 & 1,0 & 1,0 & 3,0 & 3,0 \\
\hline UFLA07-05 & 1,0429 & 2,5 & 3,5 & 1,33 & 3,0 & 3,0 & 1,5 & 3,0 \\
\hline UFLA07-08 & 1,0437 & 3,0 & 2,5 & 1,50 & 3,5 & 2,0 & 3,5 & 3,5 \\
\hline UFLA07-09 & 1,0605 & 1,0 & 1,9 & 1,05 & 2,0 & 1,0 & 5,0 & 1,0 \\
\hline UFLA07-10 & 1,0717 & 2,0 & 5,0 & 1,25 & 4,0 & 2,5 & 3,5 & 2,0 \\
\hline UFLA07-11 & 1,0336 & 2,0 & 2,5 & 1,40 & 2,0 & 1,5 & 2,0 & 2,0 \\
\hline UFLA07-12 & 1,0369 & 2,5 & 2,0 & 1,27 & 3,0 & 1,5 & 4,5 & 1,0 \\
\hline UFLA07-14 & 1,0349 & 4,0 & 2,9 & 1,30 & 2,0 & 3,0 & 3,0 & 2,0 \\
\hline UFLA07-15 & 1,0700 & 4,5 & 3,0 & 2,45 & 1,0 & 1,5 & 3,5 & 1,5 \\
\hline UFLA07-16 & 1,0257 & 2,0 & 3,0 & 1,20 & 3,0 & 2,5 & 4,0 & 2,5 \\
\hline UFLA07-17 & 1,0493 & 2,0 & 3,5 & 0,97 & 3,5 & 1,5 & 3,0 & 3,5 \\
\hline UFLA07-18 & 1,0323 & 3,0 & 5,0 & 1,50 & 2,5 & 1,5 & 2,0 & 4,0 \\
\hline UFLA07-19 & 1,0510 & 4,0 & 2,0 & 1,53 & 4,5 & 5,0 & 5,0 & 2,0 \\
\hline UFLA07-20 & 1,0553 & 1,0 & 3,0 & 1,20 & 4,5 & 2,0 & 2,0 & 3,5 \\
\hline UFLA07-21 & 1,0910 & 5,0 & 5,0 & 2,73 & 1,0 & 1,0 & 3,0 & 2,5 \\
\hline UFLA07-22 & 1,0420 & 2,0 & 4,9 & 0,95 & 5,0 & 4,0 & 2,0 & 3,0 \\
\hline UFLA07-23 & 1,0361 & 2,5 & 3,0 & 1,25 & 2,5 & 1,5 & 4,0 & 1,5 \\
\hline UFLA07-24 & 1,0409 & 1,0 & 2,0 & 1,40 & 2,0 & 2,0 & 2,0 & 2,5 \\
\hline UFLA07-26 & 1,0472 & 5,0 & 4,9 & 1,40 & 2,0 & 1,0 & 3,0 & 3,0 \\
\hline UFLA07-27 & 1,0524 & 1,5 & 4,5 & 1,23 & 4,0 & 4,5 & 4,5 & 1,5 \\
\hline UFLA07-29 & 1,0377 & 4,0 & 3,5 & 1,47 & 3,5 & 3,0 & 4,0 & 2,0 \\
\hline UFLA07-31 & 1,0333 & 3,0 & 1,5 & 1,25 & 3,0 & 2,5 & 3,5 & 2,5 \\
\hline UFLA07-37 & 1,0615 & 3,0 & 4,0 & 1,43 & 1,5 & 1,0 & 2,5 & 3,0 \\
\hline UFLA07-40 & 1,0690 & 5,0 & 2,5 & 1,45 & 2,0 & 5,0 & 5,0 & 2,5 \\
\hline UFLA07-41 & 1,0692 & 5,0 & 2,5 & 1,70 & 4,5 & 2,5 & 1,5 & 3,5 \\
\hline UFLA07-42 & 1,0601 & 2,5 & 5,0 & 1,20 & 4,5 & 4,0 & 3,5 & 2,0 \\
\hline UFLA07-43 & 1,0680 & 3,0 & 4,0 & 1,40 & 2,0 & 2,0 & 4,0 & 3,0 \\
\hline UFLA07-45 & 1,0993 & 3,5 & 4,0 & 1,25 & 1,0 & 1,0 & 4,0 & 2,0 \\
\hline UFLA07-46 & 1,0318 & 1,5 & 4,5 & 1,15 & 3,5 & 4,0 & 3,0 & 2,5 \\
\hline UFLA07-48 & 1,0487 & 3,0 & 2,9 & 1,20 & 1,0 & 1,0 & 3,0 & 3,0 \\
\hline UFLA07-49 & 1,0666 & 1,5 & 1,5 & 1,05 & 4,0 & 3,5 & 4,0 & 1,0 \\
\hline UFLA07-51 & 1,0580 & 2,0 & 4,5 & 1,25 & 2,0 & 2,0 & 3,0 & 3,0 \\
\hline UFLA07-53 & 1,0665 & 3,5 & 1,5 & 1,40 & 2,5 & 2,5 & 3,0 & 3,5 \\
\hline Média & 1,0511 & 2,97 & 3,28 & 1,78 & 2,86 & 2,40 & 3,23 & 2,53 \\
\hline Desvio-padrão & 0,0170 & 1,21 & 1,07 & 1,26 & 1,14 & 1,16 & 0,98 & 0,84 \\
\hline
\end{tabular}

${ }^{(1)}$ Valores altos para doçura e baixos para as demais características são considerados desejáveis para consumo humano. 
e a testemunha comercial 'Brazlândia-Rosada'. Entretanto, alguns genótipos apresentaram múltiplas aptidões, pois foram considerados aptos para produção de etanol, alimentação animal e consumo humano, tais como: UFLA07-12, UFLA07-31, UFLA07-43, UFLA07-49 e UFLA07-53. Estes três últimos também foram aptos para uso como alimentos funcionais, mais ricos em vitamina $\mathrm{A}$.

\section{Conclusões}

1. O índice de seleção é eficiente para identificar aptidões para genótipos de batata-doce.

2. Os genótipos UFLA07-05, UFLA07-10, UFLA07-12, UFLA07-24, UFLA07-31, UFLA07-43, UFLA07-49 e UFLA07-53 são considerados aptos para produção de etanol.

3. Os genótipos UFLA07-08, UFLA07-12, UFLA07-15, UFLA07-18, UFLA07-21, UFLA07-24, UFLA07-27, UFLA07-31, UFLA07-43, UFLA07-49 e UFLA07-53 são considerados aptos para alimentação animal.

4. Os genótipos UFLA07-01, UFLA07-05, UFLA07-12, UFLA07-16, UFLA07-31, UFLA07-42, UFLA07-43, UFLA07-49 e UFLA07-53 e as testemunhas 'Palmas' e 'Brazlândia-Branca' são aptos para consumo humano.

5. Os genótipos UFLA07-12, UFLA07-31, UFLA07-43, UFLA07-49 e UFLA07-53 apresentam múltiplas aptidões.

\section{Agradecimentos}

À Fundação de Amparo à Pesquisa do Estado de Minas Gerais, ao Conselho Nacional de Desenvolvimento Científico e Tecnológico, à Coordenação de Aperfeiçoamento de Pessoal de Nível Superior, à Universidade Federal de Lavras e à Fundação de Apoio ao Ensino, Pesquisa e Extensão, pelo apoio financeiro; e à empresa HortiAgro Sementes Ltda., pela disponibilização de infraestrutura para realização deste trabalho.

\section{Referências}

ALMEIDA-MURADIAN, L.B. de; PENTEADO, M. de V.C. Carotenoids and provitamin A value of some Brazilian sweet potato cultivars (Ipomoea batatas Lam.). Revista de Farmácia e Bioquímica, v.28, p.145-154, 1992.
AMARAL FILHO, J.P.R. do; FORNASIERI FILHO, D.; FARINELLI, R.; BARBOSA, J.C. Espaçamento, densidade populacional e adubação nitrogenada na cultura do milho. Revista Brasileira de Ciência do Solo, v.29, p.467-473, 2005.

AZEVEDO, S.M. de; FREITAS, J.A. de; MALUF, W.R.; SILVEIRA, M.A. da. Desempenho de clones e métodos de plantio de batata-doce. Acta Scientiarum. Agronomy, v.22, p.901-905, 2000.

AZEVEDO, S.M. de; MALUF, W.R.; SILVEIRA, M.A. da; FREITAS, J.A. de. Reação de clones de batata-doce aos insetos de solo. Ciência e Agrotecnologia, v.26, p.545-549, 2002.

BARBOSA, M.H.P.; PINTO, C.A.B.P. Eficiência de índices de seleção na identificação de clones superiores de batata. Pesquisa Agropecuária Brasileira, v.33, p.149-156, 1998.

BIOETANOL de cana-de-açúcar: energia para o desenvolvimento sustentável. Rio de Janeiro: BNDES, 2008. 316p. Disponível em: $<$ http://www.bioetanoldecana.org/pt/download/bioetanol.pdf $>$. Acesso em: 22 abr. 2009

CARDOSO, A.D.; VIANA, A.E.S.; MATSUMOTO, S.N.; BONFIM NETO, H.; KHOURI, C.R.; MELO, T.L. Características físicas e sensoriais de clones de batata-doce. Ciência e Agrotecnologia, v.31, p.1760-1765, 2007.

CENTRO INTERNACIONAL DE LA PAPA. CIP sweetpotato facts. Lima: CIP, 2001. Disponível em: <http://www.cipotato.org/market/ Sweetpfacts/swtpfact.htm>. Acesso em: 21 abr. 2009.

CRUZ, C.D.; REGAZZI, A.J. Modelos biométricos aplicados ao melhoramento genético. 2.ed. Viçosa: UFV, 2002. 390p.

HAGENIMANA, V.; K'OSAMBO, L.M.; CAREY, E.E. Potential of sweetpotato in reducing vitamin A deficiency in Africa. 1998. Available at: <http://www.cipotato.org/publications/program reports/97_98/34vitami.pdf $>$. Accessed on: 3 Oct. 2011.

LEMOS, L.B.; OLIVEIRA, R.S. de; PALOMINO, E.C.; SILVA, T.R.B. da. Características agronômicas e tecnológicas de genótipos de feijão do grupo comercial Carioca. Pesquisa Agropecuária Brasileira, v.39, p.319-326, 2004.

MASSAROTO, J.A. Características agronômicas e produção de silagem de clones de batata-doce. 2008. 73p. Tese (Doutorado) Universidade Federal de Lavras, Lavras.

RUIZ, M.E.; PEZO, D.; MARTINEZ, L. The use of sweet potato (Ipomoea batatas, (L.) Lam) in animal feeding: I agronomic aspects. Tropical Animal Production, v.5, p.144-151, 1980.

SILVEIRA, M.A. Batata-doce: uma nova alternativa para a produção de etanol. In: INSTITUTO EUVALDO LODI. Álcool combustível. Brasília: IEL, 2008. p.109-122.

SOUZA, A.B. de. Avaliação de cultivares de batata-doce quanto a atributos agronômicos desejáveis. Ciência e Agrotecnologia, v.24, p.841-845, 2000.

TANAKA, R.T.; MASCARENHAS, H.A.A.; REGITANO-D'ARCE, M.A.B.; GALLO, P.B. Concentração e produtividade de óleo e proteína de soja em função da adubação potássica e da calagem. Pesquisa Agropecuária Brasileira, v.30, p.463-469, 1995.

Recebido em 14 de fevereiro de 2011 e aprovado em 15 de outubro de 2011 